\title{
Tribological Performance and Lubrication Mechanism of Alkylimidazolium Dialkyl Phosphates Ionic Liquids as Lubricants for $\mathrm{Si}_{3} \mathrm{~N}_{4}-\mathrm{Ti}_{3} \mathrm{SiC}_{2}$ Contacts
}

\author{
Hai-zhong Wang, ${ }^{1,2}$ Dan Qiao, ${ }^{1,2}$ Song-wei Zhang, ${ }^{1,2}$ Da-peng Feng, ${ }^{1}$ and Jin-jun Lu ${ }^{3}$ \\ ${ }^{1}$ State Key Laboratory of Solid Lubrication, Lanzhou Institute of Chemical Physics, Chinese Academy of Sciences, \\ Lanzhou 730000, China \\ ${ }^{2}$ University of Chinese Academy of Sciences, Beijing 100049, China \\ ${ }^{3}$ College of Chemistry and Materials Science, Northwest University, Xian 710069, China
}

Correspondence should be addressed to Da-peng Feng; dpfeng@licp.cas.cn and Jin-jun Lu; jjlu@lzb.ac.cn

Received 14 February 2014; Accepted 21 March 2014; Published 16 April 2014

Academic Editor: Jinlong Jiang

Copyright (C) 2014 Hai-zhong Wang et al. This is an open access article distributed under the Creative Commons Attribution License, which permits unrestricted use, distribution, and reproduction in any medium, provided the original work is properly cited.

\begin{abstract}
The tribological performance of $\mathrm{Si}_{3} \mathrm{~N}_{4}-\mathrm{Ti}_{3} \mathrm{SiC}_{2}$ contacts lubricated by alkylimidazolium dialkyl phosphates ionic liquids (ILs) was investigated using an Optimol SRV-IV oscillating reciprocating friction and wear tester at room temperature $\left(25^{\circ} \mathrm{C}\right)$ and $100^{\circ} \mathrm{C}$. Glycerol and tributyl phosphate (TBP) were also selected as lubricants for $\mathrm{Si}_{3} \mathrm{~N}_{4}-\mathrm{Ti}_{3} \mathrm{SiC}_{2}$ contacts to study the tribological properties under the same experimental conditions for comparison. Results show that the alkylimidazolium dialkyl phosphates ILs were effective in reducing the friction and wear for $\mathrm{Si}_{3} \mathrm{~N}_{4}-\mathrm{Ti}_{3} \mathrm{SiC}_{2}$ contacts, and their performance is superior to that of glycerol and TBP. The SEM/EDS and XPS results reveal that the excellent tribological endurance of alkylimidazolium dialkyl phosphates ILs is mainly attributed to the high load-carrying capacity of the ILs and the formation of surface protective films consisting of $\mathrm{TiO}_{2}$, $\mathrm{SiO}_{x}$, titanium phosphate, amines, and nitrogen oxides by the tribochemical reactions.
\end{abstract}

\section{Introduction}

It is known that $\mathrm{Ti}_{3} \mathrm{SiC}_{2}$ is the most studied material in the system of $\mathrm{M}_{n+1} \mathrm{AX}_{n}(n=1-3)$ phases, which has a layered crystal structure and possesses the properties of both metals and ceramics. The unique properties of $\mathrm{Ti}_{3} \mathrm{SiC}_{2}$ include high strength and modulus, good damage tolerance at room temperature (RT), excellent thermal shock resistance, good electrical and thermal conductivities, easy machinability, good oxidation resistance, and low density. These unusual combinations of the properties render it a candidate structural material for high temperature applications [1-5].

Interestingly, all these unique properties of $\mathrm{Ti}_{3} \mathrm{SiC}_{2}$ are attributed to its layered structure, which is similar to that of graphite and $\mathrm{MoS}_{2}$. Thus, it is proposed that $\mathrm{Ti}_{3} \mathrm{SiC}_{2}$ is a self-lubricating material and possesses low friction coefficient $[6,7]$, and the related research about $\mathrm{Ti}_{3} \mathrm{SiC}_{2}$ has been reported with the measurement of its mechanical properties $[8,9]$. However, limited work has been carried out to evaluate the tribological behavior of $\mathrm{Ti}_{3} \mathrm{SiC}_{2}$ with liquid lubricants, which mainly focuses on the liquid lubricants of water and alcohol [10-16]. Hibi reveals that both the friction and wear of $\mathrm{Ti}_{3} \mathrm{SiC}_{2}-\mathrm{SiC}$ composite are much lower with the lubrication of ethanol than that of water, even under dry condition [14]. Unfortunately, water and alcohol could not be used under extreme conditions, such as wide temperature changes and high load.

Recently, a program has been started to illustrate the tribochemical reactions of $\mathrm{Ti}_{3} \mathrm{SiC}_{2}$ lubricating by several liquid lubricants which could be used under extreme conditions. Ionic liquids (ILs) as a unique member in the family of liquid lubricants have received increasing attention in the academic and industrial tribology fields owing to their intrinsic characteristics, such as negligible volatility, nonflammability, high 
thermal stability, and low melting point. An explosive growth of researches on ILs has been conducted in the past few years [17-22].

Research shows that the phosphates can be used to improve the antiwear and load-carrying capacity of liquid lubricant for ceramic materials [23]. Wei and Xue found that tributyl phosphate (TBP) has a little antiwear function for lubrication of ceramic because of their physical adsorption on the rubbing surfaces [24]. ILs with functional group of phosphate also can perform good tribological properties, especially at a moderate temperature [25].

Bearing this in mind, the alkylimidazolium dialkyl phosphates ILs were synthesized and evaluated as lubricants for $\mathrm{Si}_{3} \mathrm{~N}_{4}-\mathrm{Ti}_{3} \mathrm{SiC}_{2}$ contacts. Glycerol and TBP were also investigated under the same conditions for comparison. The details of the wear mechanism have been studied using scanning electron microscope with a Kevex energy dispersive $\mathrm{X}$-ray analyzer attachment (SEM) and X-ray photoelectron spectrometer (XPS).

\section{Experimental Details}

2.1. Materials Preparation. The bulk $\mathrm{Ti}_{3} \mathrm{SiC}_{2}$ sample was prepared using an in situ hot pressing/solid-liquid reaction process starting from $\mathrm{Ti}, \mathrm{Si}$, and graphite powders and $\mathrm{Al}$ powder $(3.1 \mathrm{~mol} \%)$ as a sintering additive $[15,26]$. Three kinds of powders with stoichiometric quantities were weighed, ballmilled, and then hot-pressed at $1450^{\circ} \mathrm{C}, 25 \mathrm{MPa}$ in a graphite die. The home-made $\mathrm{Ti}_{3} \mathrm{SiC}_{2}$ has the relative density of $96.4 \%$, hardness of $4.66 \mathrm{GPa}$, and surface roughness $\left(R_{a}\right)$ of $0.24 \mu \mathrm{m}$. The composition of $\mathrm{Ti}_{3} \mathrm{SiC}_{2}$ was determined by D/Max2400 (Japan) X-ray diffraction (XRD). The XRD spectrum of $\mathrm{Ti}_{3} \mathrm{SiC}_{2}$ sample is shown in Figure 1, and it can be seen that the structure of sample is polycrystalline with a small amount (less than 3 wt.\%) of TiC impurity.

The alkylimidazolium dialkyl phosphates ILs were synthesized according to the references [27, 28], and the synthesized route and molecular structures of them are shown in Figure 2. Glycerol and TBP were selected with the analytical reagent.

Several typical physical properties of the lubricants are shown in Table 1. The kinematic viscosities of the lubricants were measured using an SYP1003-III kinematic viscosity of petroleum-product measuring apparatus at $40^{\circ} \mathrm{C}$ and $100^{\circ} \mathrm{C}$. Thermogravimetric analysis (TGA) was performed on a Perkin-Elmer TGA-7 conducted in nitrogen atmosphere from $20^{\circ} \mathrm{C}$ to $600^{\circ} \mathrm{C}$ at a rate of $10^{\circ} \mathrm{C} / \mathrm{min}$. The volatilization losses of all used lubricants were tested at $100^{\circ} \mathrm{C}$ for $24 \mathrm{~h}$ according to the standard method of ASTM D972.

2.2. Friction and Wear Tests. Friction and wear tests were conducted on an Optimol SRV-IV oscillating reciprocating friction and wear tester with a ball-on-disc configuration at RT $\left(25^{\circ} \mathrm{C}\right)$ and at $100^{\circ} \mathrm{C}$. The upper ball was made of $\mathrm{Si}_{3} \mathrm{~N}_{4}$ (G5 according to ANSI/AFBMA Std 10-1989 with surface roughness $R_{a}$ of $\left.0.02 \mu \mathrm{m}\right)$ with a diameter of $10 \mathrm{~mm}$. The surface roughness $\left(R_{a}\right)$ of the $\mathrm{Ti}_{3} \mathrm{SiC}_{2}$ disc is $0.04 \mu \mathrm{m}$. Both the balls and discs were cleaned ultrasonically in ethanol for

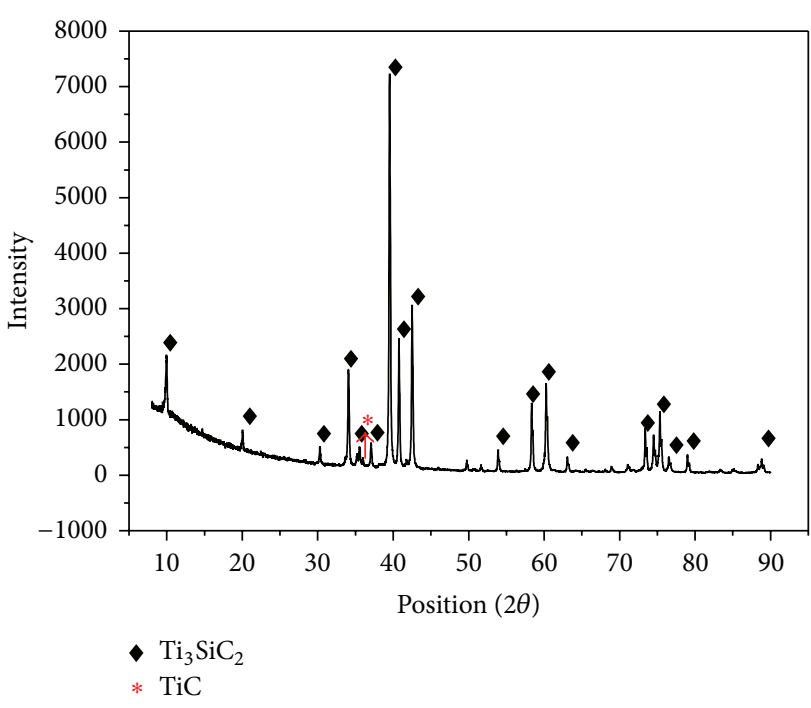

FIGURE 1: XRD spectrum of $\mathrm{Ti}_{3} \mathrm{SiC}_{2}$.

$30 \mathrm{~min}$ and allowed to dry before testing. The contact between frictional pairs was achieved by pressing the upper running ball against the lower stationary disc. The upper running ball was reciprocated at a constant frequency and stroke.

All the SRV tests were conducted under the following condition: load of $100 \mathrm{~N}$, frequency of $25 \mathrm{~Hz}$, amplitude of $1 \mathrm{~mm}$, duration of $30 \mathrm{~min}$, and a relative humidity of $20-50 \%$. Before the tests, $0.2 \mathrm{~mL}$ liquid lubricants were dropped onto the ball-disc contact area. The corresponding friction curves were recorded automatically with a charter attached to the SRV test rig. The wear volumes of lower discs were measured using a MicroXAM-3D noncontact surface mapping microscope profilometer. Three repetitive measurements were carried out under each test condition, and the average values are reported in this paper.

2.3. Measurements and Analysis. The morphologies of worn surfaces were observed by JSM-5600LV scanning electron microscopy (SEM). The X-ray photoelectron spectrometer (XPS) analysis was carried out on a PHI-5702 multifunctional $\mathrm{XPS}$, using Al-Ka radiation as the exciting source. The binding energies of the target elements were determined at pass energy of $29.35 \mathrm{eV}$, and the resolution is about $\pm 0.3 \mathrm{eV}$ with the binding energy of contaminated carbon ( $C$ s: $284.8 \mathrm{eV}$ ) as reference.

\section{Results and Discussion}

3.1. Physical Properties of ILs. Table 1 shows the physical properties of the alkylimidazolium dialkyl phosphates ILs. It can be seen that all the ILs compounds have a good viscosity index as well as a high decomposition temperature compared with glycerol and TBP. When the alkyl chains of anions increased, the viscosity of ILs became higher. And the order of the viscosity for these lubricants at $100^{\circ} \mathrm{C}$ is as follows: TBP $<$ Glycerol $<\mathrm{PEE}<\mathrm{PBE}<\mathrm{POE}$ and the details were shown in 


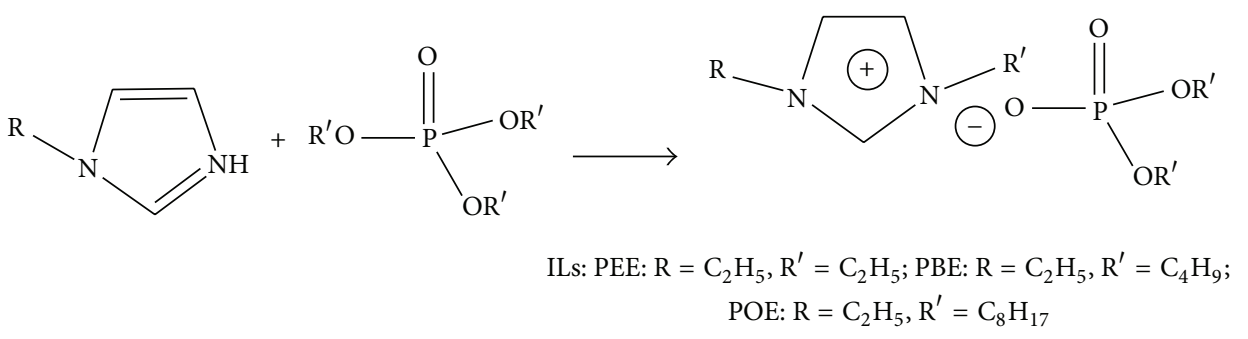

(a)

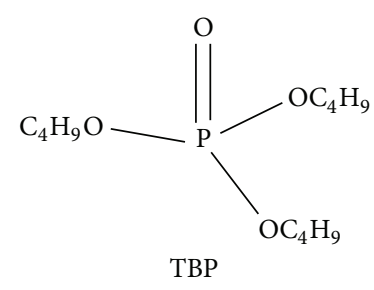

(b)

FIGURE 2: Synthesized route of the ILs of alkylimidazolium dialkyl phosphates (a) and molecular structures of TBP (b).

TABLE 1: Physical properties of the alkylimidazolium dialkyl phosphates ILs.

\begin{tabular}{lccccc}
\hline Lubricants & \multicolumn{2}{c}{} & \multicolumn{2}{c}{ Properties } \\
& $40^{\circ} \mathrm{C}$ & \multicolumn{2}{c}{ Kinetic viscosity $/ \mathrm{mm}^{2} \cdot \mathrm{s}^{-1}$} & Density/Kg·m ${ }^{-3}$ & TGA/ ${ }^{\circ} \mathrm{C}$ (onset decomposition temperature) \\
\hline PEE & 138 & 17.1 & 129 & 1125 & 275 \\
PBE & 231 & 23.9 & 115 & 1038 & 281 \\
POE & 267 & 28.4 & 117 & 1016 & 274 \\
Glycerol & 246 & 13.7 & 4.9 & 1258 & 156 \\
TBP & 3.0 & 1.1 & - & 979 & 118 \\
\hline
\end{tabular}

"-" Could not be calculated.

Table 1. And it is indicated that the alkylimidazolium dialkyl phosphates ILs were superior to the glycerol and TBP as lubricants for ceramic materials which can be used under wide temperature conditions.

The volatilization losses results of these lubricants are listed in Table 2. It can be seen that the PEE IL has the least weight loss (0.54\%) among the alkylimidazolium dialkyl phosphates ILs. TBP has the worst thermal stability with a weight loss of $53.4 \%$ and the glycerol exhibits the thermal stability with a weight loss of $8.49 \%$. These results illustrate that the alkylimidazolium dialkyl phosphates ILs possess better thermal stability and are more suitable to be used as high-temperature lubricants compared to glycerol and TBP.

\subsection{Tribological Behavior}

3.2.1. Tribological Behavior of ILs. Figures 3 and 4 exhibited the evolution of friction coefficients for $\mathrm{Si}_{3} \mathrm{~N}_{4}-\mathrm{Ti}_{3} \mathrm{SiC}_{2}$ contacts and wear volumes of $\mathrm{Ti}_{3} \mathrm{SiC}_{2}$ discs lubricated by different ILs at $25^{\circ} \mathrm{C}$ and $100^{\circ} \mathrm{C}$ under the load of $100 \mathrm{~N}$. It can be seen from Figure 3 that POE performed the highest friction coefficient among the three kinds of ILs, and the other two ILs showed the similar evolution of friction coefficients at RT. However, the lowest wear loss of ILs was obtained by the lubrication of POE, while PEE showed the highest wear loss. When the test temperature increased to $100^{\circ} \mathrm{C}$, it could be found from Figure 4 that the friction coefficient decreased remarkably as the viscosity decreased. However, the higher viscosity is benefit to improve the antiwear performance of the lubricants. Moreover, POE still exhibited the highest friction coefficient and the lowest wear loss within the three kinds of ILs. It can also be seen that PEE showed lower
TABLE 2: Volatilization losses of the lubricants $\left(100^{\circ} \mathrm{C}, 24\right.$ hours $)$.

\begin{tabular}{lccccc}
\hline Lubricants & PEE & PBE & POE & TBP & Glycerol \\
\hline Mass loss (\%) & 0.54 & 0.97 & 2.9 & 53.4 & 8.49 \\
\hline
\end{tabular}

friction coefficient and lower wear loss compared to the other two kinds of ILs at $100^{\circ} \mathrm{C}$.

In our previous work [29], it is found that anions in ILs are always involved in the tribochemical reactions, and the presence of reaction products on the worn surface makes the ILs to be good lubricants. Liu et al. also found that the structure of alkylimidazolium cation had an important effect on the tribological properties of ILs [30]. In this study, based on the aforementioned results, a conjecture can be drawn which describes that the anion with shorter alkyl chain shows higher reactivity than the anion with longer alkyl chain in the molecular structure of ILs. It also shows that lower viscosity would produce lower friction coefficient and higher wear loss under the tested conditions. Accordingly, the anion with longer alkyl chain in the molecular structure of ILs would show higher friction coefficient and the lower wear loss. In addition, ILs with longer alkyl chains in cations show the higher viscosity, which might cause higher friction coefficient and lower wear loss. Moreover, it can be seen that ILs with higher viscosity would show stronger load-carrying capacity under boundary lubrication condition from the above tribological results, which means reduction in friction coefficient depended on lower viscosity of ILs and ILs with higher viscosity showed good antiwear performance. Thus, it can also be found that the above mentioned two effects, high 


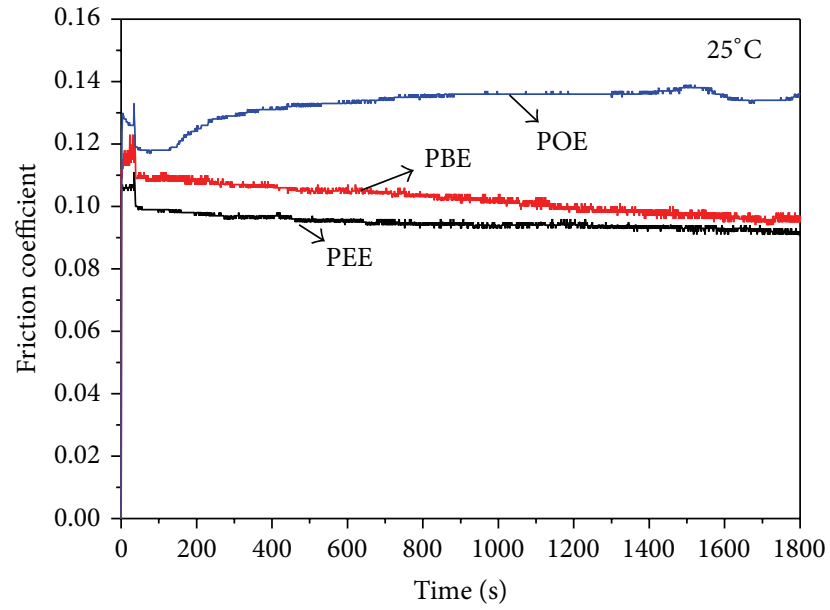

(a)

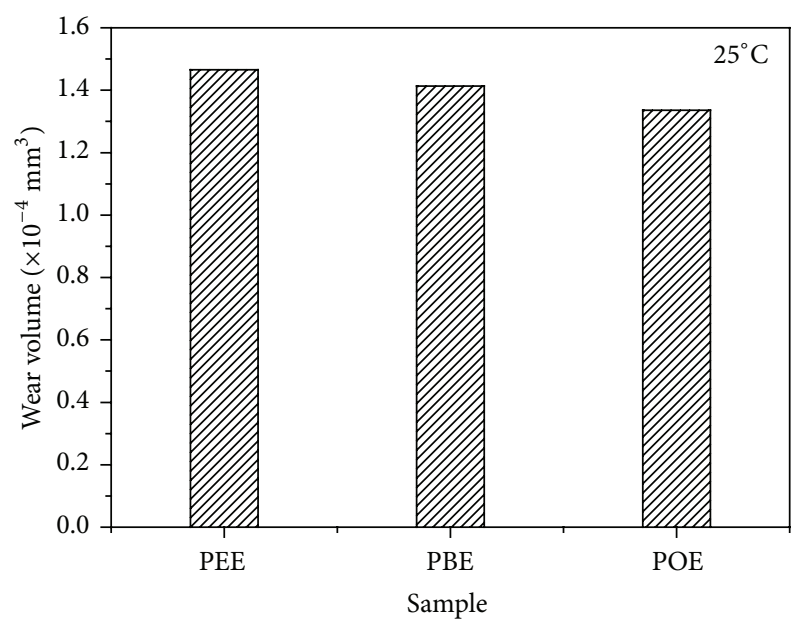

(b)

FIgURE 3: Evolution of friction coefficients (a) and wear volumes (b) of $\mathrm{Ti}_{3} \mathrm{SiC}_{2}$ discs lubricated by different ILs at $25^{\circ} \mathrm{C}$ under $100 \mathrm{~N}$.

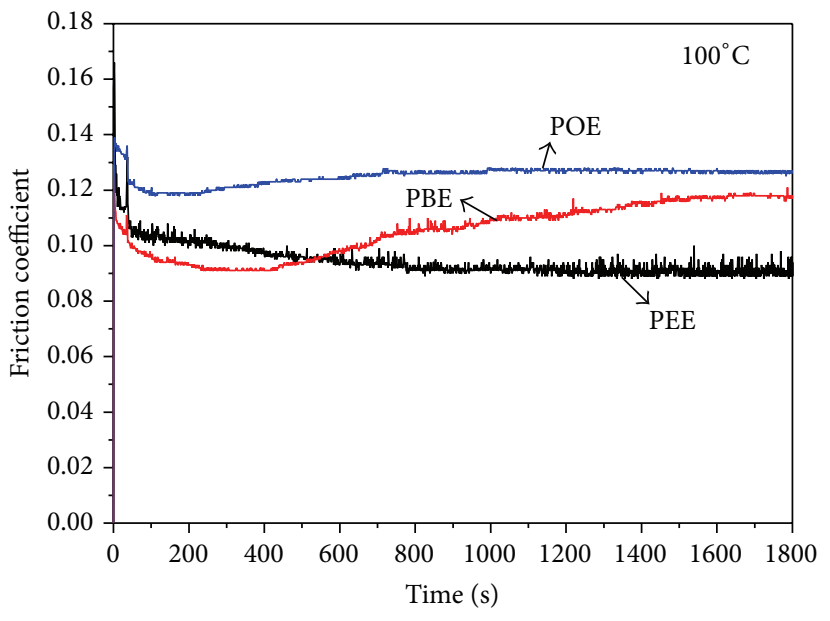

(a)

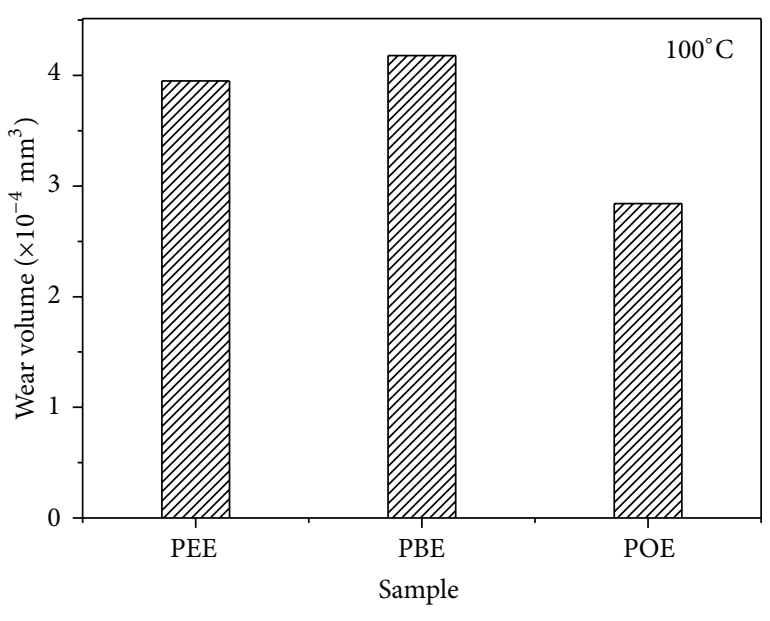

(b)

Figure 4: Evolution of friction coefficients (a) and wear volumes (b) of $\mathrm{Ti}_{3} \mathrm{SiC}_{2}$ discs lubricated by different ILs at $100^{\circ} \mathrm{C}$ under $100 \mathrm{~N}$.

reactivity and high viscosity, have exhibited more obviously synergistic effects while the temperature increased.

\subsubsection{Comparison of Tribological Behavior with Glycerol and} TBP. To verify the hypothesis that is mentioned above, the tribological experiments of TBP were also done under the same conditions, and the molecular structure of TBP is similar to the part of anion in ILs of PBE. Glycerol, which was an extensively investigated lubricant for $\mathrm{Ti}_{3} \mathrm{SiC}_{2}$, was also tested as a comparison with ILs. The compared results of the two kinds of lubricants with PBE were summarized in Figures 5 and 6 . It can be found that TBP showed much higher friction coefficient and higher wear loss both at $25^{\circ} \mathrm{C}$ and at $100^{\circ} \mathrm{C}$, which is attributed to the simple molecular structure and poor load-carrying capacity of TBP compared to that of PBE. The results were consistent to the above hypothesis that ILs with longer alkyl chains in cations would show greater load-carrying capacity under boundary lubrication condition, which means reduction in friction coefficient and wear loss. Compared with glycerol, it could be found from Figures 5 and 6 that PBE exhibited more steady friction coefficient and lower wear loss.

As a result, the high thermal stability and excellent tribological property of alkylimidazolium dialkyl phosphates ILs made it an attractive alternative to liquid lubricants for $\mathrm{Si}_{3} \mathrm{~N}_{4}-\mathrm{Ti}_{3} \mathrm{SiC}_{2}$ contacts.

3.3. Surface Analysis. SEM and three-dimensional (3D) noncontact surface measurement were employed to examine the morphologies of the wear tracks on the $\mathrm{Ti}_{3} \mathrm{SiC}_{2}$ discs. Figure 7 


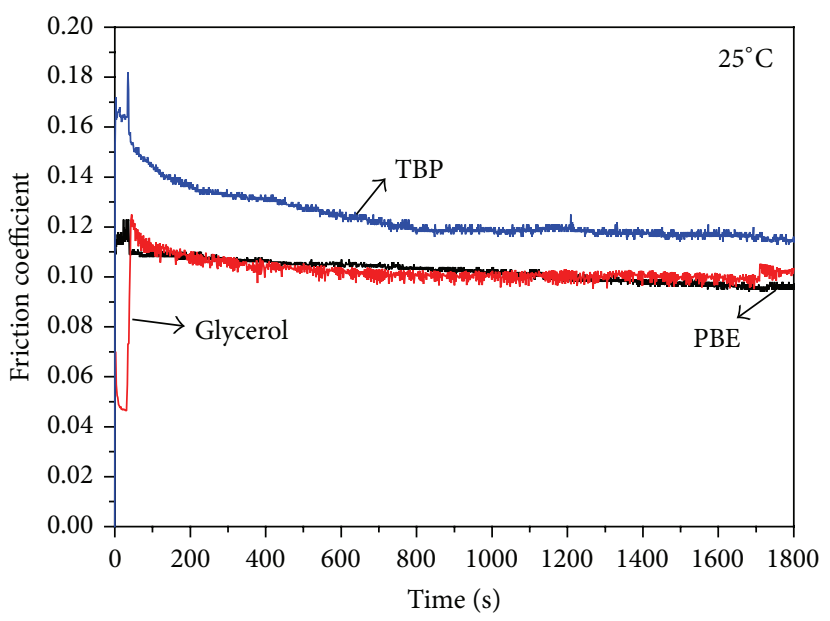

(a)

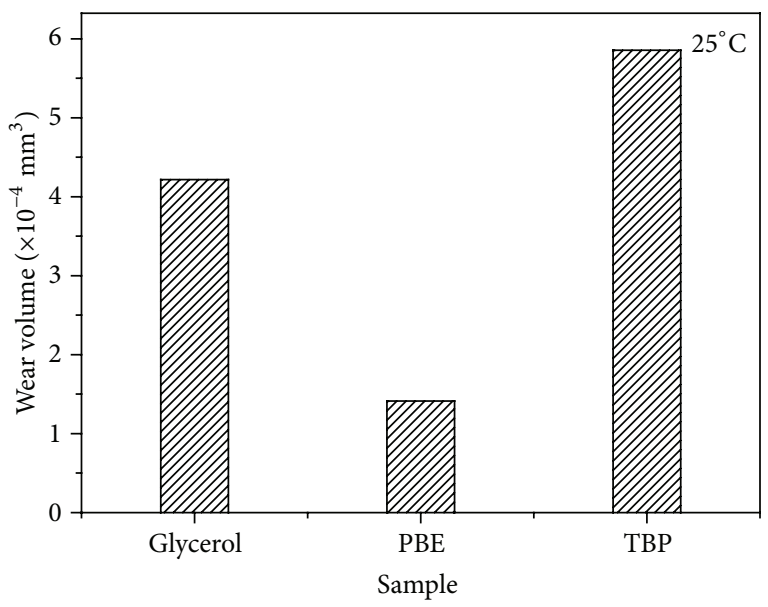

(b)

Figure 5: Evolution of friction coefficients (a) and wear volumes (b) of $\mathrm{Ti}_{3} \mathrm{SiC}_{2}$ discs lubricated by PBE, TBP, and glycerol at $25^{\circ} \mathrm{C}$ under $100 \mathrm{~N}$.

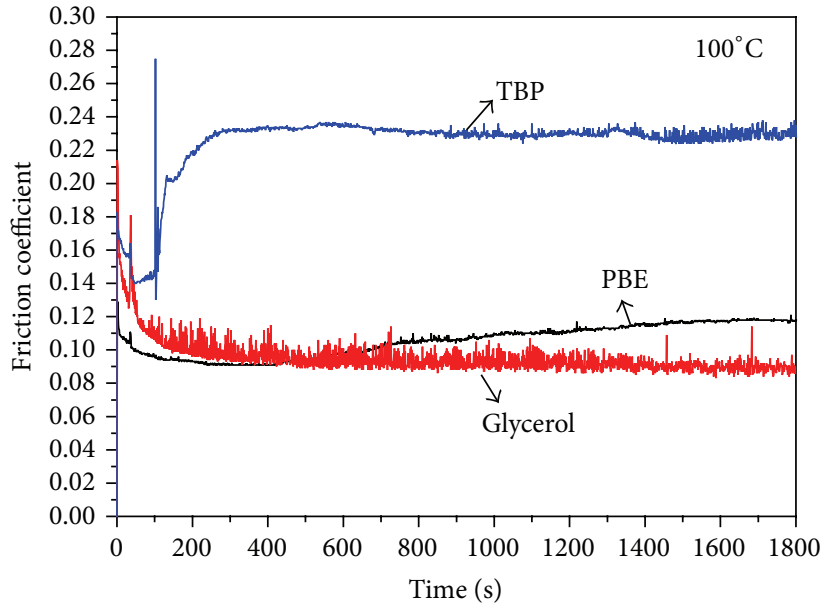

(a)

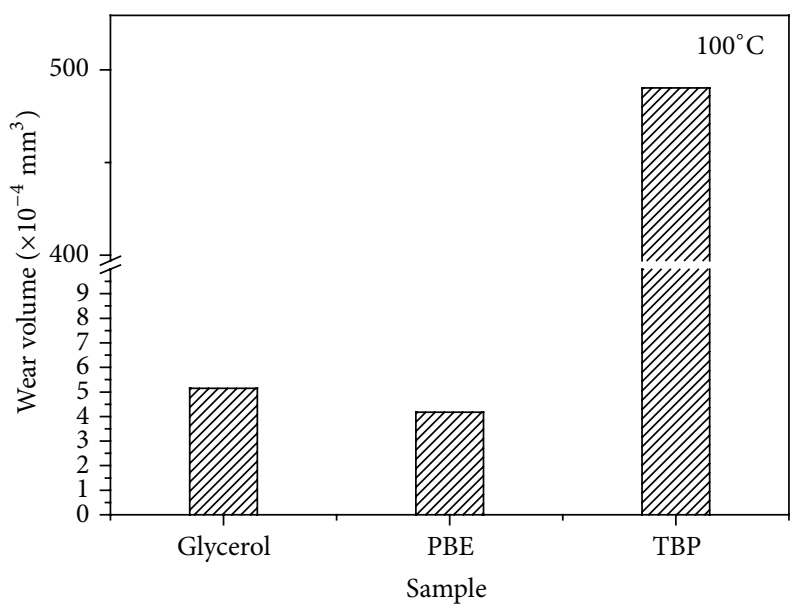

(b)

Figure 6: Evolution of friction coefficients (a) and wear volumes (b) of $\mathrm{Ti}_{3} \mathrm{SiC}_{2}$ discs lubricated by $\mathrm{PBE}$, $\mathrm{TBP}$, and glycerol at $100^{\circ} \mathrm{C}$ under $100 \mathrm{~N}$.

shows the SEM and 3D optical microscopic images of the worn surfaces lubricated by POE and glycerol under a load of $100 \mathrm{~N}$ at $100^{\circ} \mathrm{C}$. It can be seen that the worn surfaces under the lubrication of glycerol presented severe fracture and oxidation wear, whereas the worn surfaces lubricated by POE exhibited slight wear. These results highly agreed with those of high-temperature experimental results and further indicated that POE could effectively improve the wear-resistance ability for $\mathrm{Si}_{3} \mathrm{~N}_{4}-\mathrm{Ti}_{3} \mathrm{SiC}_{2}$ contacts. Figures 7(c) and 7(f) show the $3 \mathrm{D}$ optical microscopic images of the corresponding wear scars, which could clearly observe the wear scenario under the lubrication of different lubricants. The worn surfaces lubricated by glycerol (Figure 7(f)) exhibited considerably wider wear scars; however, the wear scar that is lubricated by POE (Figure 7(c)) was narrow and deeper. This result further confirms the excellent antiwear properties of POE, corresponding with the results of SEM.

To gain further insights into the complex tribochemistry of the $\mathrm{Si}_{3} \mathrm{~N}_{4}-\mathrm{ILs}-\mathrm{Ti}_{3} \mathrm{SiC}_{2}$ interface, the worn surfaces of the $\mathrm{Ti}_{3} \mathrm{SiC}_{2}$ disc lubricated with ILs were analyzed by XPS (Figure 8 ). The XPS analyses of P2p and N1s for neat POE were conducted before the tribo-tests (A), and the XPS spectra of Ti2p, Si2p, P2p, and N1s for POE were obtained after the tribo-tests (B). It can be seen that the XPS spectra of $\mathrm{Ti} 2 \mathrm{p}$ peak at $454.50 \mathrm{eV}$ correspond to $\mathrm{Ti}_{3} \mathrm{SiC}_{2}$, and the binding energy of Ti2p at $458.00 \mathrm{eV}$ and $464.10 \mathrm{eV}$ would be ascribed to $\mathrm{TiO}_{2}$ [16]. In addition, titanium phosphate $(458.80 \mathrm{eV})$ [31] could be generated on the worn surface 


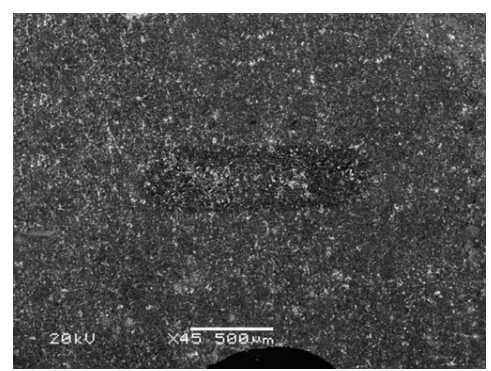

(a)

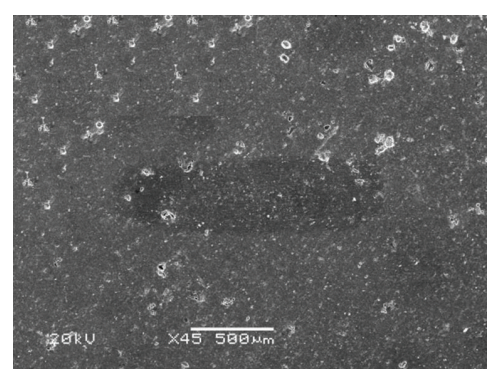

(d)

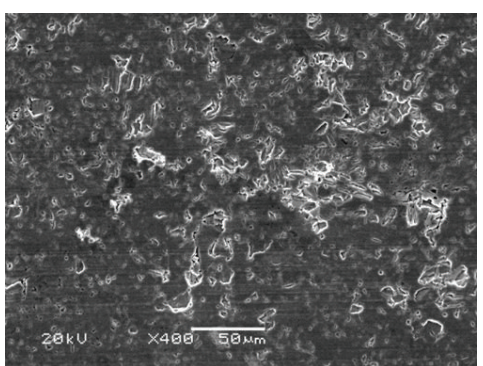

(b)

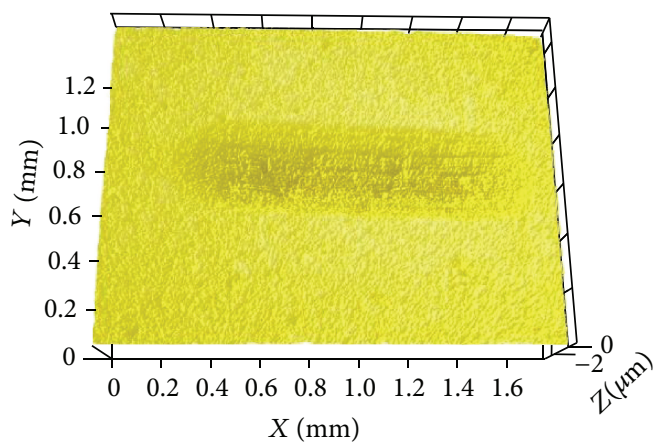

(c)

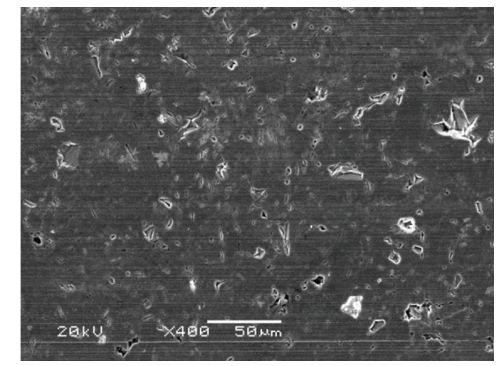

(e)

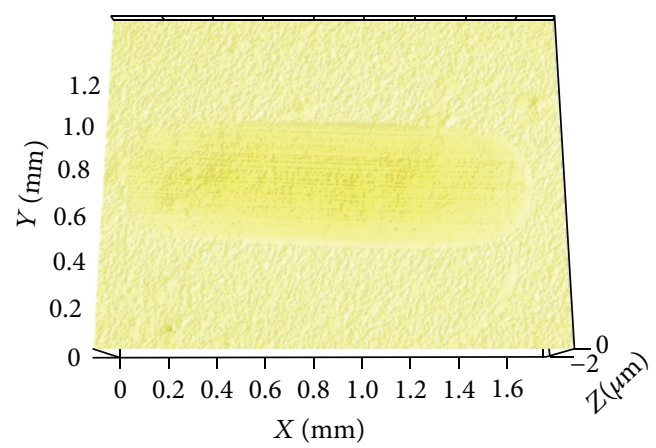

(f)

Figure 7: SEM and 3D morphologies of worn surfaces lubricated by POE and glycerol (SRV: $\left.100 \mathrm{~N}, 100^{\circ} \mathrm{C}\right)$.

during the friction process because of the interaction between the substrate and the IL lubricant.

However, a decrease for the main binding energy of the $\mathrm{Si} 2 \mathrm{p}$ peaks occurs after the friction tests, which is obtained from the comparison with the previous reported result [16]. It can be seen that the peak at $99.50 \mathrm{eV}$ corresponds to $\mathrm{SiO}_{2}$, and the peak at $100.60 \mathrm{eV}$ is referred to $\mathrm{Si}_{3} \mathrm{~N}_{4}$. There is also $\mathrm{SiO}_{x}$ present on the worn surface.

The binding energies of N1s undergo some changes compared with neat phosphate IL (the binding energy of N1s for POE appears at $401.20 \mathrm{eV}$ ). The appearance of N1s peaks at $398.70 \mathrm{eV}$ after friction can be ascribed to $\mathrm{Si}_{3} \mathrm{~N}_{4}$, which is in agreement with the Si2p peak at $100.60 \mathrm{eV}$. Amines and nitrogen oxides $(400.90 \mathrm{eV})$ [32] are produced because of the high reactivity of cation moiety. However, there is little difference for the main binding energy of the P2p peaks of phosphate IL which occurred after the friction tests. Based on the binding energy of $\mathrm{P} 2 \mathrm{p}$ at $133.25 \mathrm{eV}$, we can infer that phosphate anions are capable of reacting with $\mathrm{Ti}$ to form $\mathrm{Ti}_{3}\left(\mathrm{PO}_{4}\right)_{4}$.

Based on the above analysis, it can be concluded that ILs are easily adsorbed on the sliding surface of frictional pairs to form strongly ordered adsorbed films. Tribochemical reactions occur during the friction process, thus forming effective boundary-lubricating films which consisted of $\mathrm{TiO}_{2}$, $\mathrm{SiO}_{x}$, titanium phosphate, amines, and nitrogen oxides. Hence, the friction and wear of $\mathrm{Ti}_{3} \mathrm{SiC}_{2}$ materials are reduced.

\section{Conclusions}

Sliding friction experiments were carried out with the lubrication of alkylimidazolium dialkyl phosphates ILs. Based on the above experimental results, the following conclusions are drawn.

(1) The alkylimidazolium dialkyl phosphates ILs were effective for $\mathrm{Si}_{3} \mathrm{~N}_{4}-\mathrm{Ti}_{3} \mathrm{SiC}_{2}$ contacts lubrication and are superior to the glycerol and TBP both at $25^{\circ} \mathrm{C}$ and $100^{\circ} \mathrm{C}$; the high thermal stability and excellent tribological properties of alkylimidazolium dialkyl phosphates ILs made it an attractive alternative to liquid lubricants for $\mathrm{Si}_{3} \mathrm{~N}_{4}-\mathrm{Ti}_{3} \mathrm{SiC}_{2}$ contacts.

(2) The friction coefficient and wear loss for $\mathrm{Si}_{3} \mathrm{~N}_{4}$ $\mathrm{Ti}_{3} \mathrm{SiC}_{2}$ contacts decreased, which is attributed to the shorter alkyl chains of anion and the longer alkyl chains of cation in alkylimidazolium dialkyl phosphate ILs.

(3) The tribological mechanisms of alkylimidazolium dialkyl phosphates ILs were mainly attributed to the load-carrying capacity of the ILs and the formation of surface protective films which consisted of $\mathrm{TiO}_{2}, \mathrm{SiO}_{x}$, titanium phosphate, amines, and nitrogen oxides by the tribochemical reactions. 

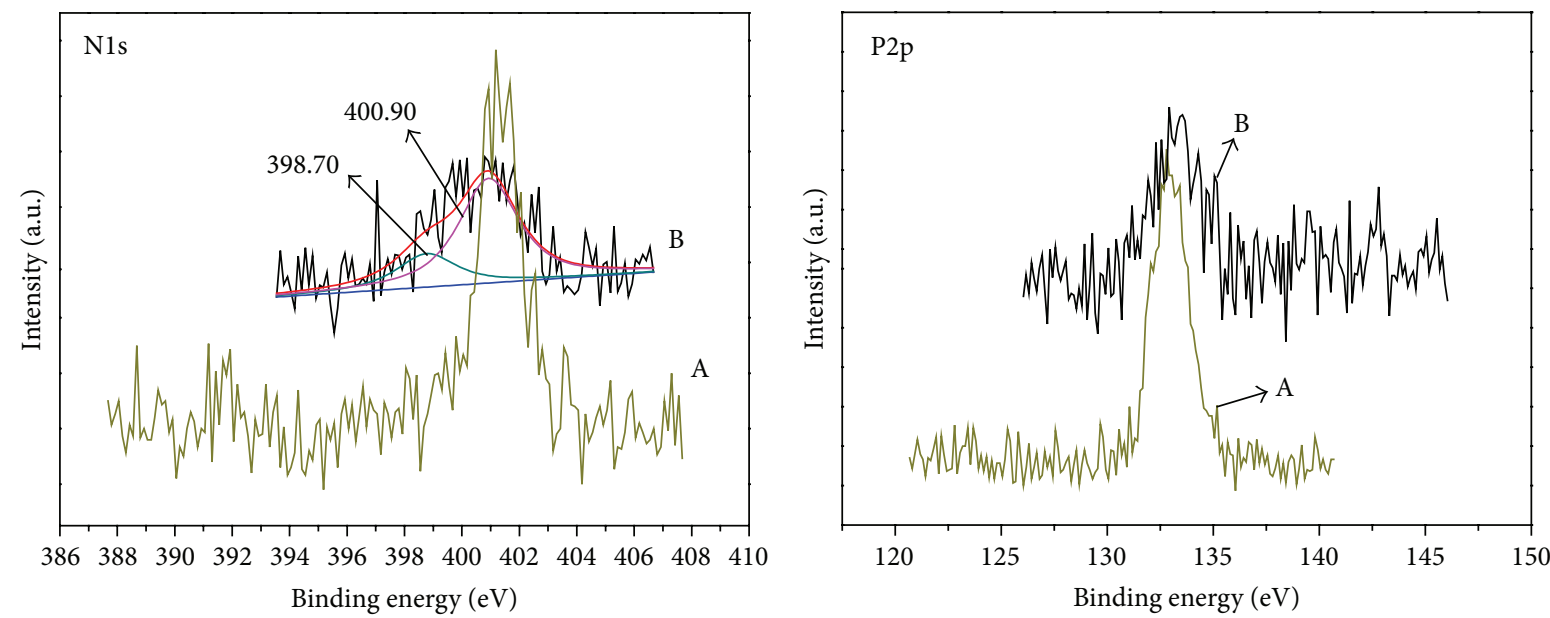

A: Pure ILs of POE

A: Pure ILs of POE

B: After lubricated

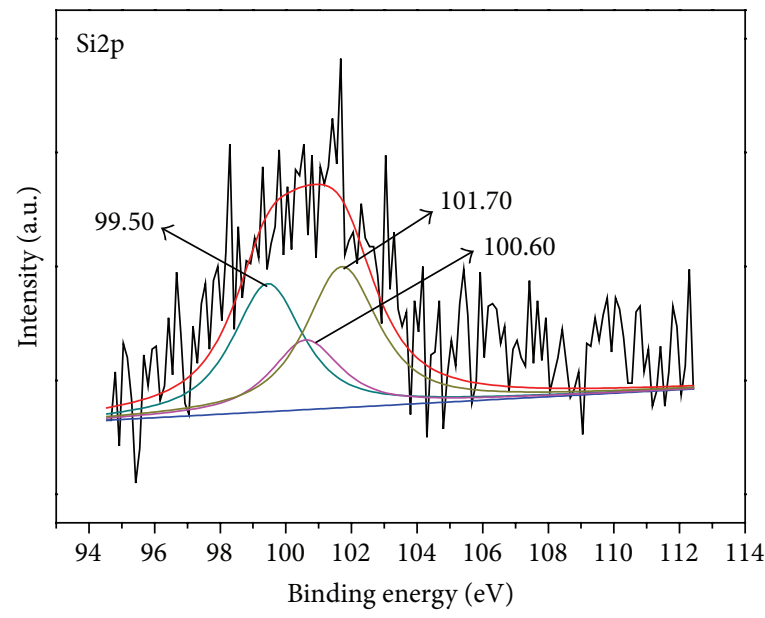

B: After lubricated

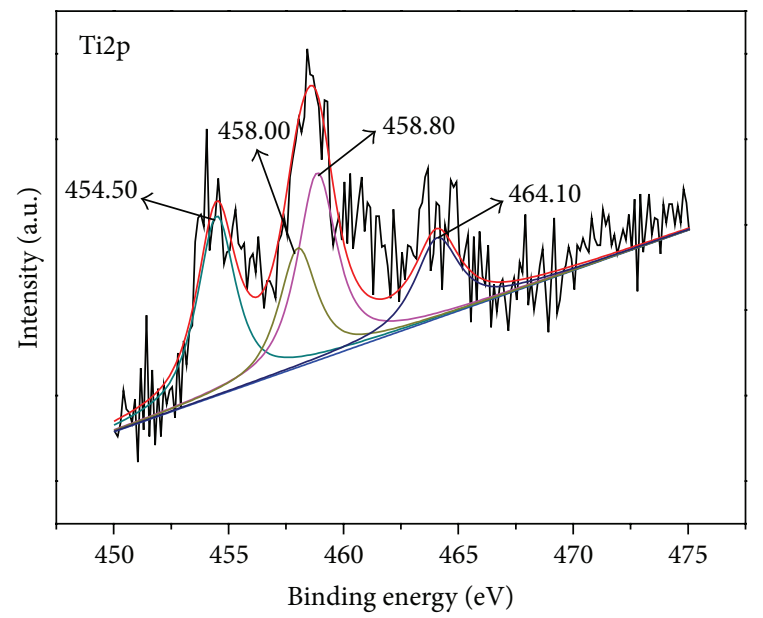

Figure 8: XPS spectra of the worn $\mathrm{Ti}_{3} \mathrm{SiC}_{2}$ surfaces lubricated by POE under $100 \mathrm{~N}$ and $100^{\circ} \mathrm{C}\left(\mathrm{SRV}: 100 \mathrm{~N}, 100^{\circ} \mathrm{C}\right)$.

\section{Conflict of Interests}

The authors declare that there is no conflict of interests regarding the publication of this paper.

\section{Acknowledgments}

The authors acknowledge financial support from the National Key Basic Research Program of China (973) (2013CB632301) and the National Natural Science Foundation of China (51175492).

\section{References}

[1] M. W. Barsoum and T. El-Raghy, "Synthesis and characterization of a remarkable ceramic: $\mathrm{Ti}_{3} \mathrm{SiC}_{2}$," Journal of the American Ceramic Society, vol. 79, no. 7, pp. 1953-1956, 1996.

[2] S. Myhra, J. W. B. Summers, and E. H. Kisi, " $\mathrm{Ti}_{3} \mathrm{SiC}_{2}$ - a layered ceramic exhibiting ultra-low friction," Materials Letters, vol. 39, no. 1, pp. 6-11, 1999.
[3] M. W. Barsoum, " $\mathrm{M}_{N+1} \mathrm{AX}_{N}$ phases: a new class of solids; thermodynamically stable nanolaminates," Progress in Solid State Chemistry, vol. 28, no. 1-4, pp. 201-281, 2000.

[4] A. Souchet, J. Fontaine, M. Belin, T. Le Mogne, J.-L. Loubet, and M. W. Barsoum, "Tribological duality of $\mathrm{Ti}_{3} \mathrm{SiC}_{2}$," Tribology Letters, vol. 18, no. 3, pp. 341-352, 2005.

[5] J. L. Zeng, S. F. Ren, and J. J. Lu, "Phase evolution of $\mathrm{Ti}_{3} \mathrm{SiC}_{2}$ annealing in vacuum at elevated temperatures," International Journal of Applied Ceramic Technology, vol. 10, pp. 527-539, 2013.

[6] Y. Zhang, G. P. Ding, Y. C. Zhou, and B. C. Cai, " ${ }^{T i}{ }_{3} \mathrm{SiC}_{2}$ self-lubricating ceramic," Materials Letters, vol. 55, pp. 285-289, 2002.

[7] D. Sarkar, B. Basu, S. J. Cho, M. C. Chu, S. S. Hwang, and S. W. Park, "Tribological properties of $\mathrm{Ti}_{3} \mathrm{SiC}_{2}$," Journal of the American Ceramic Society, vol. 88, no. 11, pp. 3245-3248, 2005.

[8] T. El-Raghy, A. Zavaliangos, M. W. Barsoum, and S. R. Kalidindi, "Damage mechanisms around hardness indentations in $\mathrm{Ti}_{3} \mathrm{SiC}_{2}$," Journal of the American Ceramic Society, vol. 80, no. 2, pp. 513-516, 1997.

[9] M. Radovic, M. W. Barsoum, T. El-Raghy, J. Seidensticker, and S. Wiederhorn, "Tensile properties of $\mathrm{Ti}_{3} \mathrm{SiC}_{2}$ in the $25-1300^{\circ} \mathrm{C}$ 
temperature range," Acta Materialia, vol. 48, no. 2, pp. 453-459, 2000.

[10] M. W. Barsoum and T. El-Raghy, "Synthesis and characterization of a remarkable ceramic: $\mathrm{Ti}_{3} \mathrm{SiC}_{2}$," Journal of the American Ceramic Society, vol. 79, no. 7, pp. 1953-1956, 1996.

[11] A. Crossley, E. H. Kisi, J. W. B. Summers, and S. Myhra, "Ultralow friction for a layered carbide-derived ceramic, $\mathrm{Ti}_{3} \mathrm{SiC}_{2}$, investigated by lateral force microscopy (LFM)," Journal of Physics D: Applied Physics, vol. 32, no. 6, pp. 632-638, 1999.

[12] Z. Sun, Y. Zhou, and S. Li, "Tribological behavior of $\mathrm{Ti}_{3} \mathrm{SiC}_{2}-$ based material," Journal of Materials Science and Technology, vol. 18, no. 2, pp. 142-145, 2002.

[13] A. Souchet, J. Fontaine, M. Belin, T. L. Mogne, J.-L. Loubet, and M. W. Barsoum, "Tribological duality of $\mathrm{Ti}_{3} \mathrm{SiC}_{2}$," Tribology Letters, vol. 18, no. 3, pp. 341-352, 2005.

[14] Y. Hibi, K. Miyake, T. Murakami, and S. Sasaki, “Tribological behavior of SiC-reinforced $\mathrm{Ti}_{3} \mathrm{SiC}_{2}$-based composites under dry condition and under lubricated condition with water and ethanol," Journal of the American Ceramic Society, vol. 89, no. 9, pp. 2983-2985, 2006.

[15] Z.-K. Du, S.-F. Ren, J.-B. Wang, J.-H. Meng, and J.-J. Lu, “Tribological properties of $\mathrm{Ti}_{3} \mathrm{SiC}_{2}-\mathrm{Al}_{2} \mathrm{O}_{3}$ composite in different liquid," Tribology, vol. 30, no. 3, pp. 223-228, 2010 (Chinese).

[16] W. X. Hai, J. L. Zeng, S. F. Ren, J. H. Meng, and J. J. $\mathrm{Lu}$, "Tribological behavior and tribochemistry of self-mated $\mathrm{Ti}_{3} \mathrm{SiC}_{2}$ in ethanol," Tribology Letter, vol. 50, pp. 449-455, 2013.

[17] M. D. Bermúdez, A. E. Jiménez, J. Sanes, and F. J. Carrión, "Ionic liquids as advanced lubricant fluids," Molecules, vol.14, no. 8, pp. 2888-2908, 2009.

[18] I. Minami, "Ionic liquids in tribology," Molecules, vol. 14, no. 6, pp. 2286-2305, 2009.

[19] F. Zhou, Y. M. Liang, and W. M. Liu, "Ionic liquid lubricants: designed chemistry for engineering applications," Chemical Society Reviews, vol. 38, no. 9, pp. 2590-2599, 2009.

[20] C. A. Angell, Y. Ansari, and Z. Zhao, "Ionic Liquids: past, present and future," Faraday Discussions, vol. 154, pp. 9-27, 2012.

[21] A. E. Somers, P. C. Howlett, D. R. MacFarlane, and M. Forsyth, "A review of Ionic liquid lubricants," Lubricants, vol. 1, pp. 3-21, 2013.

[22] Z. G. Mu, F. Zhou, S. X. Zhang, Y. M. Liang, and W. M. Liu, "Effect of the functional groups in ionic liquid molecules on the friction and wear behavior of aluminum alloy in lubricated aluminum-on-steel contact," Tribology International, vol. 38, no. 8, pp. 725-731, 2005.

[23] K. Demizu, H. Ishigaki, H. Kakutani, and F. Kobayashi, "The effect of trialkyl phosphites and other oil additives on the boundary lubrication of ceramics: friction of silicon-based ceramics," Journal of Tribology, vol. 114, no. 4, pp. 653-658, 1992.

[24] J. J. Wei and Q. J. Xue, "Tribochemical mechanisms of $\mathrm{Si}_{3} \mathrm{~N}_{4}$ with additives," Wear B, vol. 162-164, pp. 1068-1072, 1993.

[25] L. Zhang, D. P. Feng, and B. Xu, "Tribological characteristics of alkylimidazolium diethyl phosphates ionic liquids as lubricants for steel-steel contact," Tribology Letters, vol. 34, no. 2, pp. 95101, 2009.

[26] S. F. Ren, J. H. Meng, J. Lu, and S. Yang, "Tribological behavior of $\mathrm{Ti}_{3} \mathrm{SiC}_{2}$ sliding against Ni-based alloys at elevated temperatures," Tribology Letters, vol. 31, no. 2, pp. 129-137, 2008.

[27] X.-C. Jiang, C.-Y. Yu, J. Feng, C.-X. Li, and Z.-H. Wang, "Synthesis and application of ionic liquid 1-butyl-3-methylimidazolium dibutyl phosphate," Journal of Beijing University of Chemical Technology, vol. 33, no. 1, pp. 5-7, 2006.
[28] Z.-G. Mu, F. Zhou, S.-X. Zhang, Y.-M. Liang, and W.-M. Liu, "Preparation and characterization of new phosphonylsubstituted imidazolium ionic liquids," Helvetica Chimica Acta, vol. 87, no. 10, pp. 2549-2555, 2004.

[29] S. W. Zhang, L. T. Hu, D. Qiao, D. P. Feng, and H. Z. Wang, "Vacuum tribological performance of phosphoniumbased ionic liquids as lubricants and lubricant additives of multialkylated cyclopentanes," Tribology International, vol. 66, pp. 289-295, 2013.

[30] X. Q. Liu, F. Zhou, Y. M. Liang, and W. M. Liu, "Tribological performance of phosphonium based ionic liquids for an aluminum-on-steel system and opinions on lubrication mechanism," Wear, vol. 261, no. 10, pp. 1174-1179, 2006.

[31] http://srdata.nist.gov/xps/.

[32] M. R. Cai, Y. M. Liang, M. H. Yao, Y. Q. Xia, F. Zhou, and W. M. Liu, "Imidazolium ionic liquids as antiwear and antioxidant additive in poly(ethylene glycol) for steel/steel contacts," ACS Applied Materials and Interfaces, vol. 2, no. 3, pp. 870-876, 2010. 

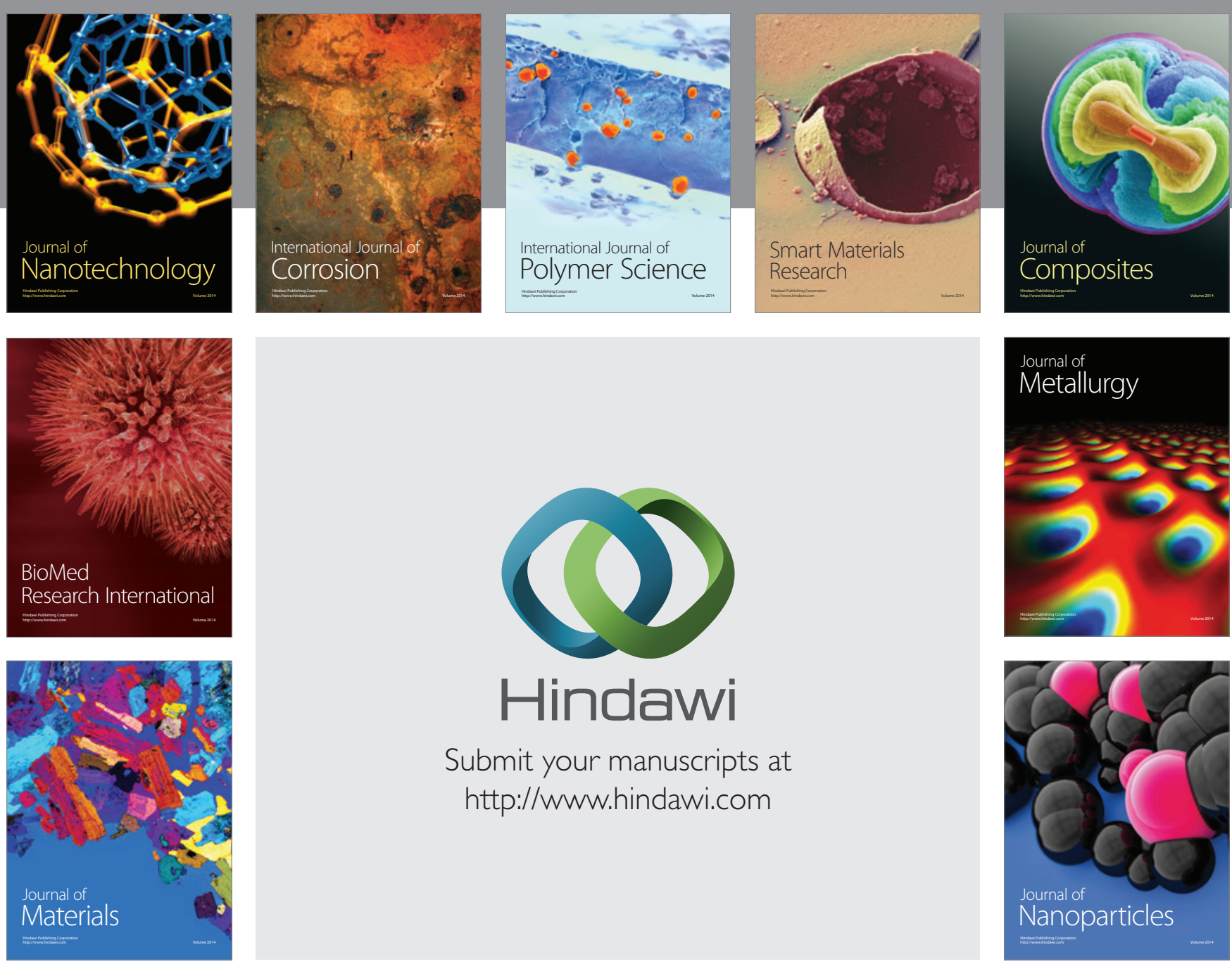

Submit your manuscripts at http://www.hindawi.com
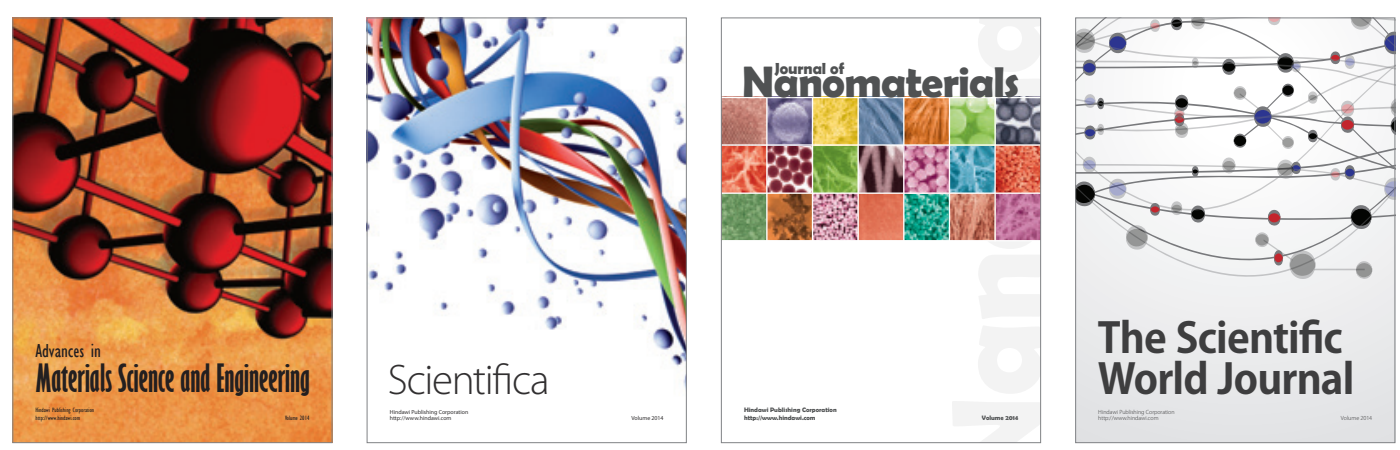

\section{The Scientific World Journal}
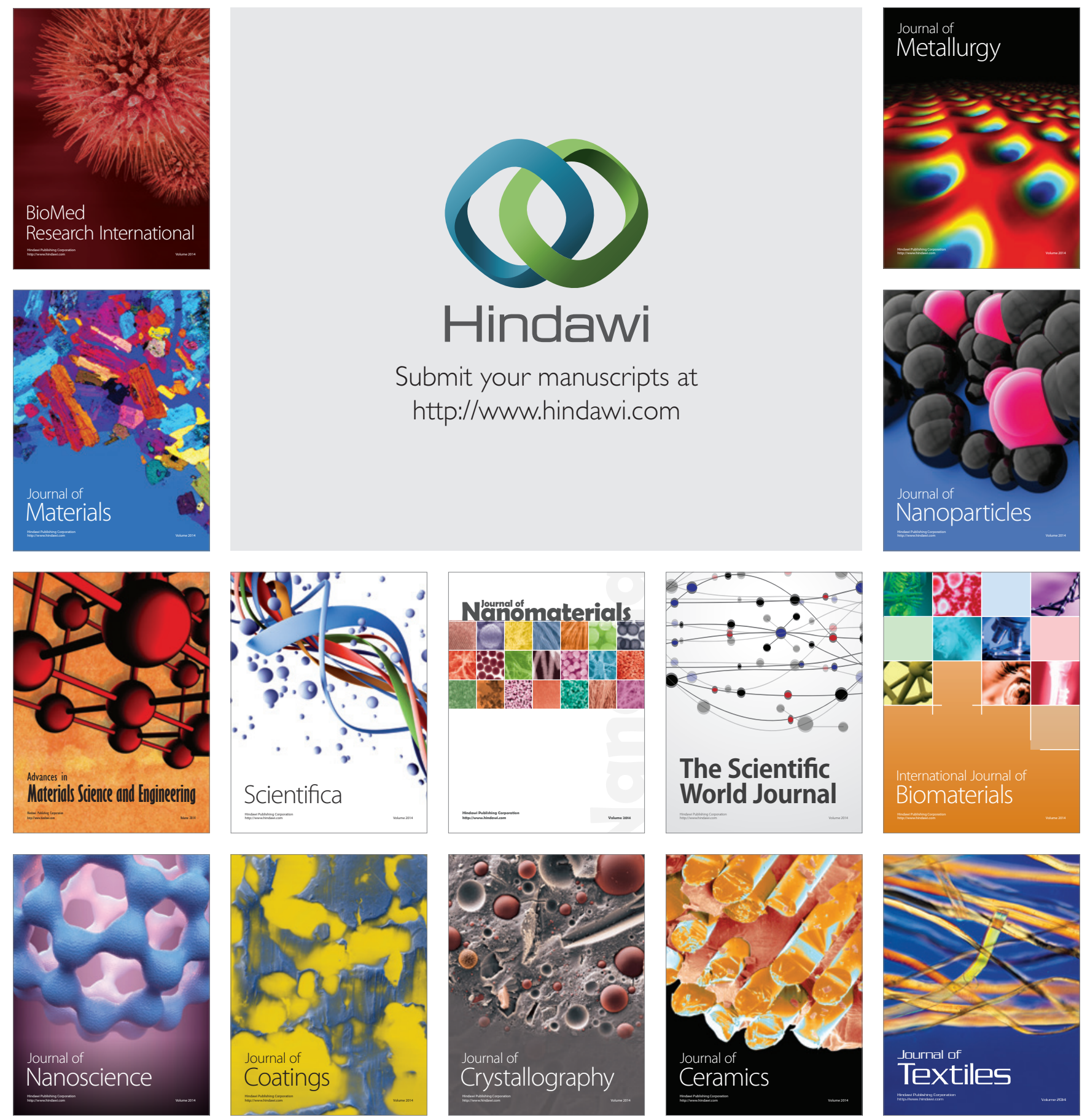